\title{
"Olhe para a sua pele": análise transversal do conhecimento populacional sobre o câncer de pele
}

\author{
"Look at your skin": cross-cutting analysis of population knowledge about skin cancer \\ "Cuide su piel ": análisis transversal del conocimiento de la población sobre el cáncer de \\ piel
}

Laís Amabile Andrade ${ }^{*}$, Luísa Ferrari Luz¹, Gabriela Souza Diniz Ricardo1, Lícia Berberich Melo, Paula Batista Ferreira ${ }^{1}$, Fernanda Cambraia Ferreira ${ }^{1}$, Luciana Monteiro Gontijo ${ }^{1}$, Anna Clara Colen Porto ${ }^{1}$, Luísa Tavares de Azevedo',Gláucia dos Santos Vianna'.

\section{RESUMO}

Objetivo: Avaliar o conhecimento populacional, atitudes e práticas sobre neoplasias de pele assim como a relevância de um projeto de extensão na área da Dermatologia. Métodos: Trata-se de um estudo transversal descritivo com a participação de 196 pacientes atendidos em um ambulatório universitário localizado na cidade de Belo Horizonte, Minas Gerais. A pesquisa analisa as características sociodemográficas dos voluntários e posteriormente investiga o conhecimento dos envolvidos acerca do câncer de pele e demais aspectos relacionados à neoplasia em questão através de um questionário autoaplicável. $O$ estudo foi aprovado por Comitê de Ética em Pesquisa. Resultados: Apesar do Brasil ser considerado um país com alta incidência solar, os cuidados com a pele da população não são suficientes em sua grande maioria. Em níveis educacionais mais altos podemos observar a adoção de diferentes, e mais de uma, medidas de proteção. É perceptível que a campanha e sua divulgação não estão atingindo uma quantidade populacional adequada, independente do grau de escolaridade. Conclusão: Os resultados do estudo mostram que a campanha contra o câncer de pele realizada anualmente pela SBD não é conhecida por parte da população e a conscientização desse público é fundamental, enfatizando a importância do diagnóstico precoce na melhora do prognóstico.

Palavras-chave: Câncer de pele, Prevenção, Melanoma, Dermatologia.

\begin{abstract}
Objective: To evaluate the population's knowledge, attitudes and practices about skin neoplasms as well as the relevance of an extension project in the area of Dermatology. Methods: This is a cross-sectional descriptive study with the participation of 196 patients seen at a university clinic located in the city of Belo Horizonte, Minas Gerais. The research analyzes the socio-demographic characteristics of the volunteers and subsequently investigates the knowledge of those involved about skin cancer and other aspects related to the neoplasia in question through a self-administered questionnaire. The study was approved by the Research Ethics Committee. Results: Despite the fact that Brazil is considered a country with a high solar incidence, the skin care of the population is not sufficient in the vast majority. At higher educational levels, we can observe the adoption of different, and more than one, protective measures. It is noticeable that the campaign and its dissemination is not reaching an adequate population, regardless of the level of education. Conclusion: The results of the study show that the campaign against skin cancer carried out annually by the SBD is not known by the population and awareness of this public is fundamental, emphasizing the importance of early diagnosis in improving the prognosis.
\end{abstract}

Keywords: Skin cancer, Prevention, Melanoma, Dermatology.

${ }^{1}$ Faculdade Ciências Médicas de Minas Gerais, Belo Horizonte - MG. *E-mail: lais_aa@hotmail.com

SUBMETIDO EM: 10/2021

ACEITO EM: 11/2021

PUBLICADO EM: 11/2021 


\section{RESUMEN}

Objetivo: Evaluar los conocimientos, actitudes y prácticas de la población sobre las neoplasias cutáneas, así como la relevancia de un proyecto de extensión en el área de Dermatología. Métodos: se trata de un estudio descriptivo transversal con la participación de 196 pacientes atendidos en una clínica universitaria ubicada en la ciudad de Belo Horizonte, Minas Gerais. La investigación analiza las características sociodemográficas de los voluntarios y posteriormente investiga el conocimiento de los implicados sobre el cáncer de piel y otros aspectos relacionados con la neoplasia en cuestión a través de un cuestionario autoadministrado. El estudio fue aprobado por el Comité de Ética en Investigación. Resultados: A pesar de que Brasil es considerado un país con alta incidencia solar, el cuidado de la piel de la población no es suficiente en la gran mayoría. En los niveles educativos superiores, podemos observar la adopción de diferentes, y más de una, medidas de protección. Se nota que la campaña y su difusión no está llegando a una población adecuada, independientemente del nivel educativo. Conclusión: Los resultados del estudio muestran que la campaña contra el cáncer de piel que realiza anualmente el SBD no es conocida por la población y la concienciación de este público es fundamental, enfatizando la importancia del diagnóstico precoz para mejorar el pronóstico.

Palabras clave: Cáncer de piel, Prevención, Melanoma, Dermatología.

\section{INTRODUÇÃO}

A Liga Acadêmica de Dermatologia Clínica e Cirúrgica (LADECC) realizou o projeto de extensão "Olhe para a sua pele", com início no ano de 2016, que se baseou na orientação da população em praças e parques públicos de Belo Horizonte a respeito da importância de atentar-se às lesões de pele e à possíveis características de malignidade. Além disso, outras orientações foram realizadas, abordando, por exemplo, a importância da utilização de filtro solar em um país com grande incidência de radiação ultravioleta, como o Brasil (SOCIEDADE BRASILEIRA DE DERMATOLOGIA, 2006).

Os projetos de extensão acadêmica representam uma forma de intervenção na comunidade cujos objetivos são, dentre outros, promover a saúde e bem-estar coletivo. O que se percebe na atualidade é a mudança de paradigmas, no qual a modificação voltada para um indivíduo é vista como necessária para construir o conhecimento nas comunidades (TRICKETT EJ, et al., 2011).

O tema principal abordado pelo projeto "Olhe para a sua pele" é o melanoma, um tumor maligno caracteristicamente agressivo e que afeta mais comumente a pele. Raramente, pode envolver outros locais, como mucosa, intestinos, cérebro ou úvea. Embora possa se manifestar em qualquer idade, cerca de $50 \%$ dos casos de melanoma cutâneo recém-diagnosticados se apresentam em pacientes com idade entre $35 \mathrm{e}$ 65 anos. Pacientes com pele ou cabelos claros, longo tempo de exposição ao sol ou outras formas de radiação ultravioleta, nevos múltiplos, imunossupressão ou história familiar de melanoma parecem estar sob maior risco de melanoma e devem ser aconselhados sobre estratégias preventivas de proteção solar tais como o uso de filtro solar, bonés, chapéus, viseiras, roupas com proteção ultravioleta e através do autoexame da pele, bem como a consulta periódica a um dermatologista (KIBBI N, et al., 2016; STRATTON DB e LOESCHER LJ, 2020).

As lesões suspeitas são tipicamente caracterizadas pela análise da lesão quanto à presença de assimetria, bordas irregulares, variação de cor (manchada, tons de marrom, preto, cinza e branco), diâmetro maior do que 6 milímetros e a evolução da lesão quanto ao seu tamanho, formato, superfície (relevo, sangramento, formação de crostas), nuances de cor ou sintomas (coceira, sensibilidade). O conhecimento dos aspectos que caracterizam as lesões de pele malignas proporciona um diagnóstico mais rápido, preciso e eficaz, além de um autoexame da pele mais criterioso, possibilitando que sejam diagnosticadas precocemente e com isso o paciente tenha um melhor prognóstico (GARRIDO AQ, et al., 2020; GARG A, et al., 2014).

A pele merece destaque no campo da oncologia, tendo em vista os variados tipos de câncer que podem se manifestar, como o carcinoma basocelular, o carcinoma espinocelular e o melanoma. É importante ressaltar que o Carcinoma Basocelular ( $\mathrm{CBC}$ ), um câncer de pele maligno, não-melanoma, das células basais 
da epiderme é caracteristicamente de crescimento lento e localmente invasivo. É o tipo mais comum de câncer de pele não-melanoma, particularmente entre os caucasianos, com incidência crescente entre muitos subgrupos, como mulheres mais jovens. Geralmente, ocorre na pele exposta ao sol, com cerca de $80 \%$ aparecendo na cabeça e no pescoço e 15\% aparecendo no tronco (HENRIKSON NB, et al., 2018).

Faz-se importante ressaltar também o Carcinoma Espinocelular (CEC), câncer cutâneo maligno comum, não-melanoma, de queratinócitos epidérmicos. Os fatores de risco para CEC cutâneo incluem idade maior que 50 anos, pele ou cabelos claros, exposição crônica à luz Ultravioleta (UV), imunossupressão ou história familiar ou pessoal de câncer de pele não melanoma (FIRNHABER JM, 2012).

Tendo isso em vista, é válido destacar a importância do presente projeto para população, visto que o câncer de pele não melanoma é o mais frequente do Brasil e corresponde a $30 \%$ dos tumores malignos. Além disso, cerca de $30 \%$ a $50 \%$ dos pacientes com câncer de pele não melanoma terão outro câncer de pele não melanoma dentro de 5 anos. Já o câncer de pele melanoma, apesar de sua baixa prevalência, é um câncer de elevada mortalidade (SILVA ESD, et al; WERNLI KJ, et al., 2016).

Estudos demonstram que aproximadamente $53 \%$ dos melanomas são descobertos pelo próprio paciente, enquanto $26 \%$ são identificados por profissionais médicos. $17 \%$ são descobertos por familiares e $3 \%$ por outros. Estes dados demonstram a relevância do autoexame como forma de diagnóstico precoce do câncer de pele (KELATI A, et al., 2017).

O câncer de pele é a forma mais incidente e prevenível dos tipos de cânceres. Segundo estimativas do Instituto Nacional de Câncer (INCA), para cada ano do triênio 2020-2022 serão esperados 177 mil novos casos de câncer de pele não melanoma. Esses dados apontam a significância do câncer de pele como um problema de saúde pública, que pode ser contido no âmbito das prevenções primária e secundária. A prevenção primária no contexto do câncer de pele abrange ações educativas, que orientam, conscientizam e esclarecem a população acerca do tema. Em relação a prevenção secundária, destaca-se a importância do rastreamento e do diagnóstico precoce (INCA, 2020; BARDINI G, et al., 2012).

As doenças dermatológicas são bastante comuns e cerca de $60 \%$ dos atendimentos na atenção primária são devido a queixas de pele. Alguns estudos demonstram que cerca de $90 \%$ dos pacientes com doenças dermatológicas não são corretamente diagnosticados. Estes dados evidenciam a relevância da Dermatologia nos atendimentos do Sistema Único de Saúde (SUS). Dessa forma, torna-se fundamental a ampliação do diálogo entre os serviços com o objetivo de amenizar as dificuldades enfrentadas na atenção primária no que se refere à conduta diante das afecções dermatológicas. Gomes, Moura e Aguiar (2012) reforçam a necessidade de se estimular o estudo e o cuidado com a pele através do desenvolvimento de materiais didáticos e da realização de ações de prevenção e promoção principalmente com o envolvimento de alunos da graduação com o intuito de fazer com que o diagnóstico das doenças que acometem a pele seja cada vez mais preciso (GOMES TM, et al., 2012).

Nesse cenário, faz-se importante destacar também a relevância das campanhas para a prevenção do câncer de pele. Para isso, a Sociedade Brasileira de Dermatologia (SBD) realiza periodicamente a campanha intitulada Dezembro Laranja, que se trata de uma iniciativa com o objetivo de atentar o público alvo sobre prevenção e diagnóstico das neoplasias de pele. Os médicos envolvidos na ação realizam um exame gratuito da população e fornecem orientação quanto aos hábitos de exposição solar e como se proteger corretamente. O principal propósito da campanha é conscientizar os brasileiros acerca dos riscos provenientes da exposição solar exagerada e desprotegida e diagnosticar de forma precoce potenciais lesões de pele malignas, proporcionando tratamento rápido e consequentemente reduzindo a mortalidade e aumentando a sobrevida dos pacientes (SOCIEDADE BRASILEIRA DE DERMATOLOGIA, 2006).

Tendo isso em vista, o projeto "Olhe para a sua pele" foi desenvolvido com o intuito de avaliar se a população conhece os principais tipos de câncer de pele e, dessa forma, orientar e educar a população em parques e praças públicas de Belo Horizonte com relação às principais características de malignidade, de modo a gerar conscientização sobre o tema e promover o autocuidado da população com a pele. A expectativa no momento do desenvolvimento do projeto era que os entrevistados apresentassem um bom nível de conhecimento a respeito do câncer de pele, porém uma baixa adesão às medidas preventivas. 


\section{MÉTODOS}

Trata-se de um estudo do tipo transversal e neste projeto buscou-se avaliar o nível de conhecimento da população sobre o câncer de pele, bem como avaliar a relevância do projeto de extensão acadêmica na área de dermatologia. Os participantes foram selecionados de forma aleatória e por conveniência no Ambulatório de uma instituição de ensino e também em parques e praças públicas localizadas na região centro sul de Belo Horizonte.

Foram incluídas na pesquisa pessoas com mais de 18 anos de idade, independente do sexo e raça, que estavam dispostas a ouvir as explicações dos acadêmicos e também a responder o questionário. Os entrevistados sempre foram questionados quanto ao interesse em responder o questionário e somente 0 fizeram quando demonstrado interesse na pesquisa. Caso a pessoa não se encaixasse nos quesitos acima ocorreu a exclusão da mesma. O estudo foi realizado com 196 participantes, de acordo com cálculo realizado para determinação dessa amostra:

$$
\mathrm{n}=\frac{\left(\mathrm{z}_{\alpha / 2}\right)^{2} \cdot \mathrm{p} \cdot \mathrm{q}}{\mathrm{d}^{2}}=\frac{(1,96)^{2} \cdot 0,5 \cdot 0,5}{(0,07)^{2}}=196
$$

Sendo $\mathrm{n}$ o número amostral, $\mathrm{z}_{\alpha / 2}$ o valor crítico, $\mathrm{p}$ a proporção populacional de indivíduos que pertence à categoria de interesse, q a proporção populacional de indivíduos que não pertence à categoria de interesse e $d^{2}$ o erro máximo permitido. Como $p$ e q são desconhecidos, utilizou-se 0,5 . O período de recrutamento da amostra ocorreu entre os meses de Agosto a Novembro de 2019.

Inicialmente houve a seleção não aleatória por conveniência no ambulatório de uma instituição de ensino superior em parques e praças públicas de Belo Horizonte onde é desenvolvido o projeto de extensão da Liga Acadêmica de Dermatologia Clínica e Cirúrgica (LADECC). Os participantes foram informados de que a participação na pesquisa era voluntária e que suas identidades seriam do conhecimento apenas da equipe de pesquisadores. Todos os esclarecimentos requisitados foram respondidos pelo pesquisador que aplicou 0 questionário. Após as explicações necessárias, ele foi convidado a assinar o Termo de Consentimento Livre e Esclarecido (TCLE).

Após essa etapa, os participantes responderam à primeira parte do questionário que continha perguntas relacionadas a dados sociodemográficos como idade, sexo e escolaridade e outras questões como o fototipo, medidas utilizadas para proteção solar e conhecimento sobre melanoma, carcinoma basocelular, carcinoma de células escamosas e sobre a campanha anual de prevenção do câncer de pele realizada pela SBD.

Posteriormente, os entrevistadores fizeram uma breve explanação sobre medidas de proteção solar, fatores de risco para o câncer de pele e a regra do ABCDE para a identificação de características de malignidade das lesões de pele. Essa explanação foi realizada por meio de folders da SBD (Dados Suplementar) que foram entregues aos participantes.

Ao final da abordagem e explicação sobre fatores de risco para câncer de pele e formas de proteção, os participantes foram convidados a responder a segunda parte do questionário em que é abordado a relevância das informações repassadas. Neste momento, os participantes foram questionados se as informações repassadas na abordagem feita pelos acadêmicos tiveram alguma relevância e trouxe algum aprendizado. Por fim, os participantes foram questionados se irão repassar essas informações a conhecidos e se haverá alguma mudança em sua forma de autocuidado com a pele. O formulário de coleta de dados encontra-se em Dados Suplementar.

Independentemente do aceite ou não na participação da pesquisa, houve a distribuição do material educativo para todas as pessoas que foram abordadas. As variáveis categóricas foram apresentadas como frequências absolutas e relativas ("n (\%)") e as variáveis numéricas, como média \pm desvio-padrão. A associação entre variáveis categóricas foi avaliada pelos testes Qui-quadrado e Exato de Fisher. As análises foram realizadas no software $R$ versão 3.4 .3 e foi considerando nível de significância de $5 \%$.

Este estudo foi aprovado pelo Comitê de Ética em Pesquisa (CEP) da instituição envolvida, com número do parecer 3.316.456. 


\section{RESULTADOS}

Foram 196 questionários aplicados no total, sendo 144 (73,5\%) indivíduos do sexo feminino e 52 (26,5\%) indivíduos do sexo masculino. A Tabela 1 mostra o $\mathrm{n}(\%)$ respondido em cada item do questionário antes de serem devidamente orientados.

Tabela 1 - Números totais e percentuais das respostas dadas durante as entrevistas.

\begin{tabular}{lc}
\hline Variáveis & $\mathbf{n}(\%)$ \\
\hline Sexo & \\
\hline Feminino & $144(73,5)$ \\
Masculino & $52(26,5)$ \\
\hline Idade & $48,8 \pm 18,1$ \\
\hline Escolaridade & $3(1,5)$ \\
\hline Sem escolaridade & $28(14,3)$ \\
Fundamental incompleto & $27(13,8)$ \\
Fundamental completo & $24(12,2)$ \\
Médio incompleto & $58(29,6)$ \\
Médio completo & $17(8,7)$ \\
Superior incompleto & $39(19,9)$ \\
Superior completo & \\
\hline Fototipo & $22(11,2)$ \\
\hline 1 & $61(31,1)$ \\
2 & $45(23,0)$ \\
3 & $32(16,3)$ \\
4 & $24(12,2)$ \\
5 & $12(6,1)$ \\
6 & \\
\hline Medidas de proteção & $91(46,4)$ \\
\hline 1. Evitar tomar sol entre 10h e 16h. & $87(44,4)$ \\
2. Uso de filtro solar & $37(18,9)$ \\
3. Roupas que cobrem a pele & $34(17,3)$ \\
4. Chapéus ou bonés & $62(31,6)$ \\
\hline Já Não protege & $151(77,0)$ \\
\hline Já ouviu falar de melanoma? falar de carcinoma espinocelular (CEC)? & $39(19,9)$ \\
\hline Já ouviu falar de carcinoma basocelular (CBC)? & $42(21,4)$ \\
\hline Já ouviu falar da campanha de prevenção do câncer de pele? & $47(24,0)$ \\
\hline Fon & \\
\hline
\end{tabular}

Fonte: Andrade LA, et al., 2020.

Já na Tabela 2, as respostas foram dadas após a orientação pautada na Cartilha sobre Câncer de Pele da SBD. Apenas dois entrevistados, dentre os 196, responderam que não transmitirão as informações dadas a outras pessoas e apenas sete não mudarão os cuidados com a pele. Vale ressaltar que essas seis pessoas já possuem um cuidado adequado com a pele.

Tabela 2 - Respostas dadas após orientação com cartilha educativa, Belo Horizonte - MG, 2020.

\begin{tabular}{lc}
\hline Perguntas & $\mathbf{n}(\%)$ \\
\hline As informações passadas são importantes? & $196(100,0)$ \\
\hline Repassará essas informações a outras pessoas? & $194(99,0)$ \\
\hline Mudará seus cuidados com a pele? & $189(96,4)$
\end{tabular}

Fonte: Andrade LA, et al., 2020.

Na Tabela 3 observou-se que, dentre as mulheres há o predomínio do fototipo 2 (pele branca, que sempre queima e bronzeia muito pouco, sendo muito sensível ao sol) e do fototipo 3 (pele morena clara, que queima moderadamente e bronzeia também moderadamente, possuindo sensibilidade normal ao sol) segundo a Classificação de Fitzpatrick. Já no sexo masculino, houve predomínio do fototipo 2 e do fototipo 4 (pele morena moderada, que queima pouco e bronzeia gradualmente, possuindo sensibilidade normal ao sol). 
No sexo feminino a medida 1 de proteção é a mais adotada (evitar tomar sol entre 10h e 16h) e menos adotada é a medida 4 (chapéus ou bonés), já no sexo masculino as medidas 1 e 2 (evitar tomar sol entre 10h e $16 \mathrm{~h}$ e uso de filtro solar) empatam em primeiro lugar e a medida 3 como a menos praticada (roupas que cobrem mais a pele). Proporcionalmente (\%) a quantidade de mulheres $(28,5 \%)$ que não utilizam nenhuma medida de proteção (medida número 5) é menor que a encontrada nos homens $(40,4 \%)$, refletindo um quadro já conhecido, onde as mulheres aderem em maior quantidade as medidas preventivas para as doenças no geral.

Tabela 3 - Relação entre o sexo, fototipo e medidas de proteção adotadas.

\begin{tabular}{lccc}
\hline \multirow{2}{*}{ Variáveis } & \multicolumn{2}{c}{ Sexo } & Valor-p \\
\cline { 2 - 3 } Fototipo & Feminino & Masculino & $0,769^{\mathrm{F}}$ \\
\hline 1 & $17(11,8)$ & $5(9,6)$ & \\
2 & $45(31,2)$ & $16(30,8)$ & \\
3 & $34(23,6)$ & $11(21,2)$ & \\
4 & $20(13,9)$ & $12(23,1)$ & \\
5 & $18(12,5)$ & $6(11,5)$ & \\
6 & $10(6,9)$ & $2(3,8)$ & $0,005^{\mathrm{Q}}$ \\
\hline Medidas de proteção & & & $0,014^{\mathrm{Q}}$ \\
\hline 1 & $76(52,8)$ & $15(28,8)$ & $0,896^{\mathrm{Q}}$ \\
2 & $72(50,0)$ & $15(28,8)$ & $0,137^{\mathrm{Q}}$ \\
3 & $28(19,4)$ & $9(17,3)$ & $0,159^{\mathrm{Q}}$ \\
\hline
\end{tabular}

Legenda: F Teste Exato de Fisher; Q Teste Qui-quadrado Fonte: Andrade LA, et al., 2020.

A Tabela 4 e a Tabela 5 relacionam a escolaridade com a adoção das medidas protetivas e se os entrevistados já ouviram sobre a campanha contra o câncer de pele realizada pela SBD. Em níveis educacionais mais altos podemos observar a adoção de diferentes, e mais de uma, medidas de proteção. É perceptível que a campanha e sua divulgação não estão atingindo uma quantidade populacional adequada, independente do grau de escolaridade.

Tabela 4 - Relação entre escolaridade e adoção de medidas de proteção.

\begin{tabular}{lccccc}
\hline \multirow{2}{*}{ Variáveis } & \multicolumn{5}{c}{ Medidas de proteção } \\
\cline { 2 - 6 } & $\mathbf{1}$ & $\mathbf{2}$ & $\mathbf{3}$ & $\mathbf{4}$ & $\mathbf{5}$ \\
\hline Escolaridade & $1(1,1)$ & $0(0,0)$ & $0(0,0)$ & $0(0,0)$ & $2(3,2)$ \\
\hline Sem escolaridade & $16(17,6)$ & $14(16,1)$ & $2(5,4)$ & $2(5,9)$ & $8(12,9)$ \\
Fundamental incompleto & $10(11,0)$ & $8(9,2)$ & $5(13,5)$ & $5(14,7)$ & $11(17,7)$ \\
Fundamental completo & $10(11,0)$ & $9(10,3)$ & $1(2,7)$ & $0(0,0)$ & $12(19,4)$ \\
Médio incompleto & $28(30,8)$ & $28(32,2)$ & $12(32,4)$ & $16(47,1)$ & $16(25,8)$ \\
Médio completo & $8(8,8)$ & $11(12,6)$ & $5(13,5)$ & $3(8,8)$ & $3(4,8)$ \\
Superior incompleto & $18(19,8)$ & $17(19,5)$ & $12(32,4)$ & $8(23,5)$ & $10(16,1)$ \\
Superior completo & & & &
\end{tabular}

Fonte: Andrade LA, et al., 2020.

Tabela 5 - Relação entre a escolaridade e o conhecimento sobre a existência da campanha contra o câncer de pele da SBD.

\begin{tabular}{lcc}
\hline \multirow{2}{*}{ Variáveis } & \multicolumn{2}{c}{ Já ouviu sobre a campanha? } \\
\cline { 2 - 3 } & Sim & Não \\
\hline Escolaridade & & $3(2,0)$ \\
Sem escolaridade & $0(0,0)$ & $25(16,8)$ \\
Fundamental incompleto & $3(6,4)$ & $21(14,1)$ \\
Fundamental completo & $6(12,8)$ & $20(13,4)$ \\
Médio incompleto & $4(8,5)$ & $47(31,5)$ \\
Médio completo & $11(23,4)$ & $11(7,4)$ \\
Superior incompleto & $6(12,8)$ & $22(14,8)$ \\
Superior completo & $17(36,2)$ &
\end{tabular}

Nota: Valor-p = 0,021 - Teste Qui-quadrado. Fonte: Andrade LA, et al., 2021. 


\section{DISCUSSÃO}

Câncer da pele é o câncer mais comum no mundo e corresponde a um terço dos casos de câncer, com estimativa de 200 mil novos casos/ano no Brasil. É quatro vezes mais frequente que o câncer de mama e próstata. O principal fator desencadeante para a formação das lesões malignas de pele é a exposição excessiva ao sol, sendo que, a população que possui pele mais clara está mais susceptível a desenvolvê-las. A maioria dos cânceres da pele são curáveis cirurgicamente quando precocemente identificados e abordados. Os principais subtipos são: CBC, CEC e melanoma. Dentre os tumores da pele, $70 \%$ correspondem ao CBC, $25 \%$ ao CEC e $5 \%$ a tumores mais raros. A chave do sucesso da abordagem do câncer da pele é a sua rápida identificação e intervenção (KIBBI N, et al., 2016).

Neste estudo pôde-se identificar que dentro da amostra, 151 entrevistados (77\%) já tinham ouvido falar sobre melanoma, mesmo não sabendo defini-lo de forma correta. Porém, o que merece destaque é a baixa porcentagem dentre os mesmo que sabiam ou ouviram falar de Carcinoma Espinocelular e Basocelular - 39 $(19,9 \%)$ e $42(21,4 \%)$ respectivamente. Além disso, fica claro que o sexo feminino adere em mais medidas preventivas para câncer de pele, refletindo um quadro conhecido no qual elas possuem maior autocuidado e aderem as diferentes campanhas de doenças no geral.

Por se tratar de um trabalho singular, não foram achados estudos e população semelhantes. Porém em um estudo quantitativo realizado por Popim RC, et al. (2008), abrangendo 33 carteiros na cidade de Botucatu, foram obtidos dados com o objetivo de investigar há quanto tempo os participantes trabalhavam na empresa e por quanto tempo se expunham ao sol, se algum deles possuía história prévia de queimaduras solares e se algum familiar já havia sido acometido por câncer. Além disso, o estudo também investigou se os participantes utilizavam alguma barreira protetiva quanto ao câncer de pele. Observou-se que uso de medidas preventivas contra os danos causados pela radiação solar estava diretamente relacionado à escolaridade dos participantes. Aqueles que se preocupam em seguir as orientações em relação à prevenção do câncer de pele relatam ainda realizar inspeção frequente das áreas mais expostas ao sol durante a ocupação por se tratar de prática incentivada pela própria empresa durante os programas educação continuada

Em outra pesquisa realizada por Castilho, et al, 2010, investigou-se os hábitos de exposição solar e o conhecimento sobre fatores de risco genético e ambiental (radiação UV) para desenvolvimento de câncer de pele entre um grupo de 68 universitários. Através desse estudo foi possível constatar que a maior parte dos participantes utilizava medidas de proteção solar, no entanto, realizavam de maneira inadequada. Ademais, foi constatado ainda que as mulheres possuem uma tendência a se protegerem mais dos danos causados pela radiação solar quando comparado aos homens. Além disso, observou-se também que amplo conhecimento quanto a radiação UV como principal fator desencadeante de mutações carcinogênicas na pele, porém a genética foi raramente associada pelos participantes como fator de risco para a carcinogênese. Em um panorama geral, os dados publicados corroboraram com nossos achados, apesar do nível de conhecimento acadêmico não ser fator influenciador (CASTILHO IG, et al.,2010).

Apesar da maioria dos participantes do estudo ter demonstrado conhecimento sobre os fatores de risco associados à exposição solar, as regiões geográficas do Brasil são heterogêneas quanto à suas características culturais, demográficas, socioeconômicas e políticas, sendo assim, as populações são submetidas a fatores de risco distintos. Assim como a exposição aos fatores de risco se diverge, a qualidade da assistência prestada nos serviços de saúde, das informações repassadas e da precisão diagnóstica dependem da região brasileira analisada. Por esse motivo, os quadros das neoplasias de pele preponderantes também se diferem regionalmente e por vezes são um reflexo da desigualdade notada por toda a extensão territorial do país (POPIM RC, et al., 2008).

Indivíduos portadores de pele mais clara, expostos rotineiramente a alta incidência de luz solar, estão mais susceptíveis a desenvolver lesões de pele potencialmente malignas. $O$ fato de grande parte dos brasileiros possuir pele clara e se expor muito ao sol sem o uso adequado de proteções físicas e mecânicas, seja por trabalho ou por lazer, justifica a alta ocorrência de câncer de pele (IM JL e ASGARI M, 2020).

A exposição constante ao sol e a longevidade cada vez maior da população são fatores agravantes importantes. Associado a isso, há ainda a crescente valorização de peles bronzeadas, bastante exploradas 
pela mídia. Sendo assim, mesmo que a proteção solar venha a ser normatizada, dificilmente os danos já causados serão revertidos e espera-se, portanto, que o problema ainda persista por todo século XXI. Uma das maneiras de tentar reverter esse estigma criado pelos meios de comunicação em relação à exposição solar é realizando intervenções educativas com o público infanto-juvenil, abordando o câncer de pele e como preveni-lo, dessa forma, o conhecimento sobre o assunto começaria a ser construído e sedimentado desde cedo (AASI SZ e HONG AM, 2020; STEELE C, 2020).

Apesar de ser um país tropical e com alta incidência solar, no Brasil, a população ainda não adquiriu a rotina de proteção solar, como uso diário de protetor solar e roupas protetivas. O fato do uso do filtro solar ainda não ser uma medida disseminada, deve-se em grande parte aos altos custos atribuídos a esses produtos, sendo fundamental o debate em torno do barateamento dessa mercadoria. O grau de escolaridade influenciou minimamente nesse quesito, mas há uma relação em que quanto maior o nível educacional mais medidas foram tomadas (BARDINI G, et al., 2012).

Considerando o exposto, é necessário realizar estudos com maior abrangência, que incluam um número maior de características da população estudada e que sejam capazes de avaliar a predisposição ao câncer de pele pela amostra estudada. Além disso, devem ainda aprofundar a análise do grau de informação dos participantes no que diz respeito aos fatores de risco e medidas protetivas que podem ser adotadas para reduzir a chance de desenvolvimento de lesões malignas de pele.

\section{CONCLUSÃO}

Os resultados do estudo mostram que a campanha contra o câncer de pele realizada anualmente pela SBD não é conhecida por parte da população (apenas 24\% dentre os 196 entrevistados já tinham ouvido falar sobre a campanha). Esses resultados denotam importância o reforço a divulgação dessa, uma vez que ela é responsável por grande conscientização e educação populacional. Além disso, as lesões de câncer da pele costumam ser silenciosas e assintomáticas e apesar dos prognósticos de cada tipo de câncer de pele serem diferentes, a maioria é passível de cura se identificados e tratados precocemente, sendo de extrema importância a busca ativa por lesões suspeitas no exame físico do paciente associada a orientações sobre possíveis sinais de alerta para lesões suspeitas, como o aumento de tamanho, mudança de forma e/ ou de cor, sangramento espontâneo e aquelas que não cicatrizam.

\section{AGRADECIMENTOS}

Agradecemos à Faculdade Ciências Médicas e ao Ambulatório Ciências Médicas pela oportunidade de realizar essa pesquisa, disponibilizando o local para a coleta de dados para a realização da pesquisa.

\section{REFERÊNCIAS}

1. AASI SZ e HONG AM. Treatment and prognosis of low-risk cutaneous squamous cell carcinoma. Abril, 2020. UpToDate.

2. BARDINI G, et al. Avaliação do conhecimento e hábitos de pacientes dermatológicos em relação ao cancer da pele. Arq. Catarin. Med, 2012; 41(2): 56-63.

3. BRUNSSEN A, et al. Impact of skin cancer screening and secondary prevention campaigns on skin cancer incidence and mortality: A systematic review. Journal of the American Academy of Dermatology, 2017; 76(1): 129-139.

4. CASTILHO IG, et al. Fotoexposição e fatores de risco para câncer da pele: uma avaliação de hábitos e conhecimentos entre estudantes universitários. Anais Brasileiros de Dermatologia, 2016; 85(2): 172-178.

5. INSTITUTO NACIONAL DO CÂNCER (INCA). Estimativa 2020. Disponível em: https://www.inca.gov.br/estimativa/introducao. Acesso em: 5 nov. 2021.

6. FIRNHABER JM. Diagnosis and treatment of basal cell and squamous cell carcinoma. American family physician, 2012; 86(2): 161-168.

7. GARG A, et al. The Integrated Skin Exam film: an educational intervention to promote early detection of melanoma by medical students. Journal of the American Academy of Dermatology, 2014; 70 (1): 115-119.

8. GARRIDO AQ, et al. Diagnosis of Cutaneous Melanoma: the Gap Between the Knowledge of General Practitioners and Dermatologists in a Brazilian Population. Journal of Cancer Education, 2020; 19:1-7. 
9. GOMES TM, et al. Dermatologia na atenção primária: um desafio para a formação e prática médica. Revista Brasileira de Educação Médica, 2012; 36(1): 125-128.

10. HENRIKSON NB, et al. Behavioral Counseling for Skin Cancer Prevention: Evidence Report and systematic Review for the US Preventive Services Task Force. JAMA, 2018; 319(11): 1143-1157.

11. KELATI A, et al. Skin cancer knowledge and attitudes in the region of Fez, Morocco: a cross-sectional study. BMC dermatology, 2017; 17(1): 2.

12. KIBBI N, et al. Kibbi, Nour et al. "Melanoma: Clinical Presentations." Cancer treatment and research, 2016; 167: 107129.

13. LIM JL, ASGARI M. Cutaneous squamous cell carcinoma (cSCC): Clinical features and diagnosis. Julho, 2020. UpToDate.

14. POPIM RC, et al. Câncer de pele: uso de medidas preventivas e perfil demográfico de um grupo de risco na cidade de Botucatu. Ciência \& Saúde Coletiva, 2008; 13(4): 1331-1336.

15. SILVA ESD, et al. Use of sunscreen and risk of melanoma and non-melanoma skin cancer: a systematic review and meta-analysis. European Journal of Dermatology, 2018; 28(2):186-201.

16. SOCIEDADE BRASILEIRA DE DERMATOLOGIA. Análise de dados das campanhas de prevenção ao câncer da pele promovidas pela Sociedade Brasileira de Dermatologia de 1999 a 2005. Anais brasileiros de dermatologia. 2006; 81 (6): 533-9.

17. STEELE C, et al. "Live Sun Smart!" Testing the effectiveness of a sun safety program for middle schoolers. Pediatric dermatology, 2020; (37)3: 504-509.

18. STRATTON DB e LOESCHER LJ. Educational interventions for primary care providers to improve clinical skin examination for skin cancer. Journal of the American Association of Nurse Practitioners, 2020; 32(5): 369-379.

19. TRICKETT EJ, et al. Advancing the Science of Community-Level Interventions. American Journal of Public Health, 2011; 101(8): 1410-1419.

20. WERNLI KJ, et al. Screening for Skin Cancer in Adults: Updated Evidence Report and Systematic Review for the US Preventive Services Task Force. JAMA, 2016; 316(4): 436-47. 